\title{
Assessment of the Coping Strategies of Flood Victims in the Builsa District
}

\author{
Fiasorgbor Doris ${ }^{1}$,, Wiafe Edward ${ }^{2}$, Tettey Caroline ${ }^{2}$, Abasiyam Mary ${ }^{1}$ \\ ${ }^{1}$ Department of Rural and Community Development, Faculty of Development Studies, Presbyterian University College, Abetifi, Ghana \\ ${ }^{2}$ Department of Environment and Natural Resources Management, Faculty of Development Studies, Presbyterian University College, Abetifi, \\ Ghana
}

\section{Email address:}

dfiasorgbor@presbyuniversity.edu.gh (F. Doris), edward.wiafe@presbyuniversity.edu.gh(W. Edward), caroline.tettey@presbyuniversity.edu.gh (T. Caroline), abassmary693@yahoo.com (A. Mary)

${ }^{*}$ Corresponding author

\section{To cite this article:}

Fiasorgbor Doris, Wiafe Edward, Tettey Caroline, Abasiyam Mary. Assessment of the Coping Strategies of Flood Victims in the Builsa District. Environment and Sustainability. Vol. 2, No. 1, 2018, pp. 17-25. doi: 10.11648/j.ajese.20180201.12

Received: July 14, 2017; Accepted: April 18, 2018; Published: May 19, 2018

\begin{abstract}
Flooding can pose substantial social and welfare problems that may continue over extended periods of time that include economic stress associated with re-building that arise as people try to recover their lives, property and relationships. This study is focused on identifying community coping strategies in relation to flood and examine the factors influencing the selection of coping strategies as well as the local government policies in relation to flood disaster management. The target population for the study is households affected by flood, who were accidentally selected at household levels. One hundred (100) respondents chosen were interviewed person to person with the use of both structured and semi- structured guides. The study indicated that the largest floods in the area in recent years occurred in 2007, 2010, 2012 and 2017. The causes were as a result of heavy rains and when neighbouring Burkina Faso opened a flood gate of the Bagre dam, releasing an enormous amount of water into the White Volta River that flowed into Ghana. During flooding, crops are submerged or washed off and animals drowned; animals like sheep, goats and cattle go days without food and often suffer foot and mouth diseases and die as a result. To cope with the flooding, the victims borrow money and food in order to survive through the flood season and some households traded their assets for money and food, taking children out of school to work, while some sent family members out to live with friends and relatives elsewhere. Pastoral farming has been adopted and the community members also engaged in activities such as sale of firewood or charcoal, income from petty trading usually by women, some travel to work mostly in southern Ghana and send food items home, thatch weaving for local roofing and twine weaving to make income. There should be policies that target the marginalised in society, such as women, children, the elderly, the physically challenged persons and the poor otherwise these groups will remain most vulnerable. Self-help measures to reduce damage to property and stress caused by flooding should also be encouraged.
\end{abstract}

Keywords: Coping Strategy, Flood, Builsa District

\section{Introduction}

Flooding is now the most frequent type of major disasters. The impacts of climate change are likely to increase the occurrence of flooding that happens to be the most frequent type of major disaster now a days [1]. In the era of climate change, the reliability on predictability in rainfall patterns has been reduced drastically. The frequency and severity of weather events such as floods, cyclones and hurricanes have increased unpredictably [8]. Recently, river flooding represents the most common global hazard causing phenomenal losses. Historically, floods have had devastated effects on properties and livelihoods as well as more economic losses than any other hazard.

Flood, a discharge of excessive water which exceeds the channel capacity can pose substantial social and welfare problems that may continue over extended periods of time that include economic stress associated with re-building that arise as people try to recover their lives, property and relationships. However, flooding also stands out from other 
types of disasters because, it is often possible to prevent flooding by using flood prevention measures such as moving away from rivers and other water bodies. Unfortunately, humans continue to live and work in areas threatened by flood damage; floods appear to be part of the lives of several communities in the world [2]

Ghana has experienced a sharp disparity in its weather that has recently resulted in extensive flooding currently reported in over five (6) regions of which four (5) are severely affected. The floods have caused disturbing effect to people's health, safety and destruction to properties and livelihood. The reported flooding across the country is likely to cause wreckage that communities and government is incapable to handle and or even recover from it as farmers are losing their investments in production, communities are vulnerably being displaced and infrastructure such as roads and buildings are collapsing [12].

Africanews [3] indicated that most areas of Tamale got flooded after heavy rains. Local media reported two deaths and the loss of properties running into millions of Ghana cedis. The main hospital serving the northern region, the Tamale Teaching Hospital, was not spared the floods. Flooding in parts of the country has become a perennial occurrence. It has led to calls for the government to take steps to forestall flooding rather than seeking to remedy its effects. The National Disaster Management Organization (NADMO) is called to action in times of such disasters. Their main mandate is to cushion the effects of displacements and to help affected people to piece their lives back.

The immediate impacts of flooding include loss of human life, damage to property, destruction of crops, loss of livestock, and deterioration of health conditions due to waterborne diseases. As communication links and infrastructure such as power plants, roads and bridges are damaged and disrupted, some economic activities may come to a standstill and people are forced to leave their homes making normal life to be disrupted. Similarly, disruption to industry can lead to loss of livelihoods. Damage to infrastructure also causes long-term impacts such as disruptions to supplies of clean water, wastewater treatment, electricity, transport, communication, education and health care. Loss of livelihoods can reduce the purchasing power and loss of land value in the floodplains which can leave communities economically vulnerable [1]. Floods can also traumatize victims and their families for extended periods of time. The loss of loved ones has profound impacts, especially on children. Displacement from one's home, loss of property and disruption to business and social affairs can cause continuing stress. For some people the psychological impacts can be long lasting [4].

UNISDR, [16] states that the African continent is more vulnerable than any other continent to climate change. Ghana, a West African country of about 28.21 million people (2016 estimates) has experienced several forms of natural disasters ranging from drought in the 1980s and 2006 to floods in 2007, 2010, 2012, and 2015. With continuing climate change, one could predict that several forms of floods and other natural disasters would be prominent in the near future; this would largely be due to increasing concentration leading to flash floods in many areas of Africa including Ghana [11].

According to Blaikie et al., [4] floods can bring economic and environmental benefits and this in general include sedimentation, increased amount of water of dams for irrigation and domestic purposes and also flood plains with respect to eco-systems but in most cases, preferences in dealing with the consequences are usually given to the negative effects of these natural hazards.

Since prehistoric time people have settled in flood prone areas due to favourable geographic conditions which facilitate economic growth, such as fertile lands for crop and livestock production and transportation [1]. The incidence of natural disasters has been increasing over the years, ensuing in loss of life, damage to property and devastation of the environment. The number of people at risk is also rising each year and the majority of these people are in developing countries where poverty levels are high; making them more susceptible to these disasters [15]. Losses can be high in rural areas where most of the damage is sustained by agriculture such as crops and livestock. Therefore poverty worsens when natural disasters destroy rural infrastructure.

The reliefweb [18] indicated that in Greater Accra, many homes in low lying areas in Weija and Tetegu in the Ga South Municipality have been inundated with water, as a result of the spillage of the Weija dam. In the Central Region at least 400 people have said to be rendered homeless in Twifo Praso and its environs due to floods in the area. It is reported that some affected families are stranded on islands and in need of canoes to rescue them, several hectares of farmlands have also been destroyed. The Western Region in July 2017, flood waters from River Tano and other tributaries displaced over 1,000 residents of Samreboi, Wassa Dunkwa, Aboi Nkwanta Samreboi communities within the Wassa Amenfi West District. These residents are predominantly farmers, but as the flood waters have taken over pathways to their farms, they have had to abandon their farms for days. While some residents are temporarily seeking shelter in churches and schools, others are seeking refuge with relatives on higher grounds. In Eastern Region, floods are said to affect the Ahiatroga community resulting in the collapse of 26 houses, displacing close to 100 peasant farmers. Some of the displaced residents mostly women and children are currently putting up in a church building and a classroom.

The Builsa district generally has a low relief with elevations between 150-250m above sea level [4]. The Red, White Volta and other river paths pass through quite a lot of settlements rendering the populace and their surrounding area to the dangers of floods. The five (5) sampled study communities covered in the study have various rivers and their tributaries running through them accounting for the high vulnerability to flooding.

A number of these communities experience sanitation and drainage problems. The aftermath is that any time floods happen; the livelihoods of farmers along the low-lying areas 
are at risk of flooding. The frequent failure of crops and loss of lives and property due to floods leads to decline in income, increased household costs, disintegration and high youth migration. The worst flood in August 2007 resulted in three human deaths, loss of property, with more than 1,300 households rendered homeless [12]. Again, many buildings were submerged and over 3,000 hectares of farmlands destroyed. Additionally, the floods caused outbreak of waterborne diseases including diarrhoea, cholera and malaria particularly, among children.

Floods are liable to natural hazards however human activities on the environment make worse the effects of flood hazards. In the route of the flood plains, agricultural activities can lead to degradation of environment, loss of vegetation cover results in erosion and siltation of rivers causing wellknown harm to lives and property. Intense and heavy rainfalls in July which continue through to the end of September causes high discharges and large-scale impulsive flows above the capability of the drainage systems, the yearly spillage of the Bagre Dam in Burkina Faso results in regular floods [14]. The challenge here is that the capacities of the most important drains are reduced and as heavy rains increase water volumes, the rivers give up the overload water resulting in flood. Flood cause poor harvest with emergent food insecurity, hunger and worsening poverty levels. The impact of flood disaster is felt by a good number of the poorest members of people particularly those whose livelihoods are fixed to climate sensitive sectors of the economy such as rain fed agriculture [15]. Since floods are a frequent feature in Ghana, local coping strategies are required to reduce the shocks. It is against this background that this study examines the impact of floods and coping strategies adopted by farmers in some communities in the Builsa district.

\section{Study Area}

Builsa District is one of the thirteen (13) administrative districts in the Upper East Region of Ghana. It lies between longitudes $1^{\circ} 05^{\prime}$ West and $1^{\circ} 35^{\prime}$ West and latitudes $10^{\circ} 20^{\prime}$ North and $10^{\circ} 50^{\prime}$ North. The District covers an area of 2,220 $\mathrm{km}^{2}$ and constitutes $25.1 \%$ of the total land area of the Upper East Region. It has 155 communities and eight area councils with no urban settlement (where urban settlement is community with 5000 or more residents). Thus the district is in every respect rural. The topography of the area is undulating and slopes ranging from 200 metres to 300 metres are found in the western and northern part of the District particularly around Bachonsa and Chuchuliga zones. In the valleys of Sissili, Kulpawn, Besibeli, Tono, Asibelika and Azimzim, the slopes are gentler and range from 150 to 200 metres. Inselbergs and other granitic outcrops occasionally break the monotony of the near flat surfaces. In general the low-lying nature of the land makes greater part of it liable to flooding in years of copious rains [5].

The vegetation of the Builsa District is characterized by savannah woodland and consists mostly of deciduous, widely spaced fire and drought resistant trees of varying sizes and density with dispersed perennial grasses and associated herbs. Through the activities of man, the woodland savannah has been reduced to open parkland where only trees of economic value like baobab, acacia, shea-nut, mango and dawadawa trees have been retained through time [6]. These trees satisfy domestic requirements for fuel wood and timber for local housing construction, cattle kraals, vegetable garden fences and materials for handicraft [6]. These human activities on the environment coupled with heavy rains exacerbate the flood hazard into a disaster threatening livelihoods and local infrastructure development.

Like most parts of northern Ghana, the District has mean monthly temperatures ranging between $21.9^{\circ} \mathrm{C}$ and $34.1^{\circ} \mathrm{C}$. The dry season is characterized by dry harmattan winds and wide diurnal temperature ranges. The rainy season builds up gradually from little rains in April to a maximum in AugustSeptember with irregular dry spells occurring in June or July. The rains decline sharply in September drawing to a complete halt in mid-October; setting the dry season in [6].

The district is dissected by a number of tributaries of the Red and White Volta and the Nasia river, with rainfall ranging between $85 \mathrm{~mm}$ and $1,150 \mathrm{~mm}$ annually, there is increased drainage density and risk of flooding [4].

\section{Research Design and Methodology}

The target population for the study is households that have experienced incidence of flood, who were accidentally selected at household levels. By accidental sampling, upon entering a house the first person (18 years +) that the researchers encountered who was ready and willing to offer information was interviewed. The approach gave each household in the house the same chance of being part of the selected respondents. The respondents chosen were interviewed person to person with the use of both structured and semi- structured questionnaires. These instruments were used to bring out data on people's knowledge of the effects of flooding, coping strategies and experiences of public interventions for flood management. This information is considered important in order to understand what factors influence the choice of coping mechanisms among the communities.

The key institutions charged with the responsibility for planning and managing disasters at the district level were purposively chosen. NADMO and the District Assembly officials provided information on the kind of relief support that is given to flood victims. They also shared experiences on the effects and impact of floods in the district and their activities to manage the situation.

Five (5) Assembly members as community leaders also provided information on community mobilization. All informants were purposively chosen because of their ability to give expert and institutional views about vulnerability of the flood prone communities and interventions. An interview guide was used to carry out the gather information at this stage. The questionnaires covered the following areas; 
rainfall performance and climate change issues, impact of floods on Agriculture, Health, Infrastructure, Education, Water and Sanitation, Housing and Property Vulnerable Groups due to floods, Coping Strategies and development options to deal with the problems of floods.

According to Strydom et al. [14], data a nalysis is a way of researching data by cleaning, inspecting, and modelling the data, this is because it is difficult or impossible to explain raw data. Data from various sources are gathered, reviewed and then analysed to form some sort of findings. The goal is to emphasize useful information, and suggest conclusions. Data collected from the field were compiled, collated and analysed. The use of descriptive analysis was employed to analyse data derived from the key informant interviews. Descriptive analysis was again employed to present case studies and observations by the researchers.

\section{Results and Discussion}

\subsection{Demographic and Socio-economic Characteristics}

The socio-economic characteristic of the respondents were assessed based on: age, gender, marital status, education as well as economic conditions of the households during the fieldwork time. This information could facilitate the understanding as to why and how the people act in response to floods.

\subsubsection{Distribution of Respondents by Age}

Table 1 describes the distribution of the age of the respondent for this study. The age of respondent is used in this research with the pre-assumption that the age of the respondents has a relationship by means of the way they perceive flood.

Table 1. Age of respondents.

\begin{tabular}{lll}
\hline Age of respondents & Frequency & \% \\
\hline $18-29$ & 12 & 12 \\
$29-39$ & 10 & 10 \\
$39-49$ & 39 & 39 \\
$49-59$ & 15 & 15 \\
$60+$ & 24 & 24 \\
Total & 100 & 100 \\
\hline
\end{tabular}

Respondents of all ages (18 to 60+) were represented, with larger numbers in the $39-49$ bracket and the $60+$ categories accounting for $39 \%$ and $24 \%$ of the respondents respectively. The importance of age as a factor of vulnerability can be significant in situations where physical fitness is necessary for survival. The high fatality can occur among children, elderly, or sick adults.

\subsubsection{Gender of Respondents}

The number of males interviewed was smaller at $39 \%$ compared with females at $61 \%$. This can be attributed to the fact that most male household members were engaged in activities outside the house such as funerals and farming during the survey period.

\subsubsection{Marital Status}

The findings showed that most of the respondents, constituting 53\% were married and living with their spouses. A further $34 \%$ were widows, $8 \%$ were singles, while $5 \%$ had been divorced. Female-headed households, widows/widowers and their children were generally perceived to be more vulnerable to floods as compared to their counterpart households with both spouses. This could be explained by the fact that households with both spouses are better placed both financially and psychologically. They are therefore able to respond to flood risks in a better manner than their single counterparts.

\subsubsection{Educational Level of Respondents}

The pie chart below illustrates the educational level of the respondents. It is presumed that the educational level of the respondents has a relationship with the way they perceive flood. Education is a necessary tool for understanding issues and adopting methods to reduce the impact of a disaster. The findings showed that $64 \%$ of the respondents had not gone to school at all and over $70 \%$ of this category was women. Less than $14 \%$ of the participants had gone beyond primary level education and among these $12 \%$ had completed secondary education while $10 \%$ had some post-secondary education.

The low levels of education could be attributed to high poverty levels and lack of motivation to pursue higher education. Disparities with respect to access to and control of a range of assets such as land, education levels, and legal rights are all skewed against women and children in the communities. The women have heavier time burdens, lower rates of utilization of productive resources and lower literacy rates. The results further revealed that many women had to depend on their spouses or relatives for a livelihood. These circumstances have been found to affect the women's ability to respond appropriately to flood hazards as well as their capacity to participate in flood management at both household and community levels. As stated by UNISDR [15] that low education levels have been associated with lack of wellremunerated employment and therefore less social power and fewer economic resources and physical capacity to expect, survive and recover from the effects of massive floods.

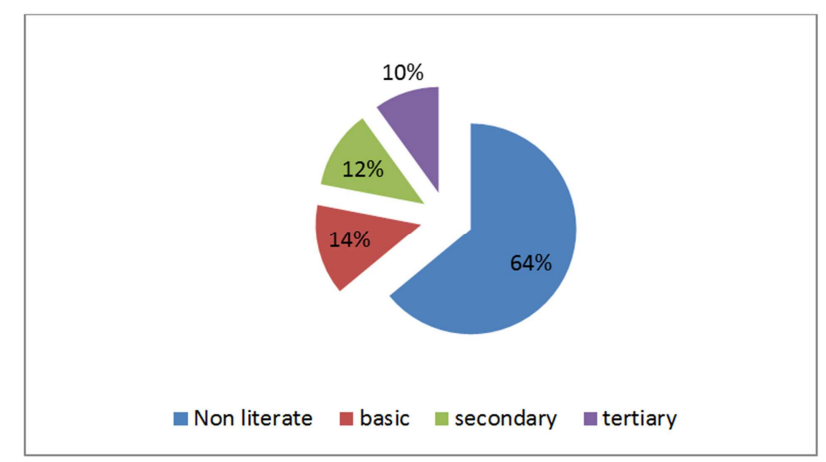

Figure 1. Educational levels of respondents.

\subsubsection{Occupation}

The Figure 2 below shows the occupation of the 
respondents. Variable occupation of respondent is considered in this research based on the assumption that occupation as part of economic activity has close relationship with the type of the coping mechanisms applied by the households to cope with flood. The main occupations in the communities in order of magnitude are agriculture, animal husbandry, forestry and related activities, $63 \%$ production, $23 \%$ trade, and services $8 \%$ and other activities $6 \%$. These together make up of all occupations in the communities. The Occupational structure of the communities is thus not very diverse. About two out of every three people in active employment is in agriculture. The ratio is about equal for both males and females. However, the proportion of females in sales work is about twice that of males.

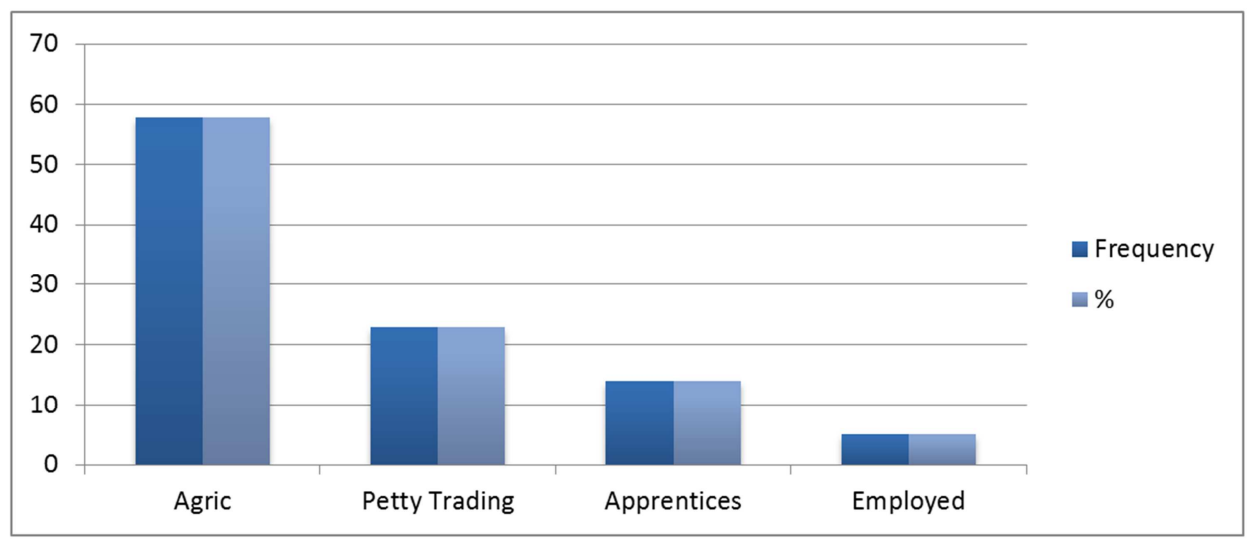

Figure 2. Occupations.

\subsection{Flood History and People's Perception of Possible Causes of Floods}

Based on the personal interview with the people, most of the respondents could recall the largest floods in the area in recent years of 2007, 2010 and 2012. Causes of floods in these areas are as a result of heavy rains, human failings in farming methods such as slash and burn which damage top soils and when neighbouring Burkina Faso opened a flood gate of the Bagre dam, releasing an enormous amount of water into the White Volta River that flowed into Ghana. However, the need to attribute disasters to some supernatural forces was still felt by a substantial number of respondents.

The study established that there was a difference between the experience of flooding and the frequency of its occurrence among the inhabitants. It was established that out of the 100 respondents, $80 \%$ of the households experienced flooding, $98 \%$ said floods occurs once every year. On another hand, 20\% have not had flood waters affecting them directly, $2 \%$ of the respondents stated that floods occurred twice annually.

Table 2. Causes of flood.

\begin{tabular}{lll}
\hline Causes & Frequency & Percentage \\
\hline Heavy rain & 45 & 45 \\
Environmental degradation & 20 & 20 \\
Spillage of Barge dam & 35 & 35 \\
All of the above & 10 & 10 \\
Total & 100 & 100 \\
\hline
\end{tabular}

\subsection{Why People Are Still Living in These Areas}

The study found that the main reason for the people to stay in the study areas is ancestral properties and access to market places is the last reason to be considered by the people. Results from this study also indicated that for these communities, the advantages of living close to flood plains far outweighed the health risks associated with flooding. Although flooding was viewed as a recurring problem; this implies that for these communities, despite the inherent flood risks, it also determines their immediate economic survival.

Inappropriate land use near water bodies and the flood plains leads to an increase in the sediment of the river. The sediments fill up the channel in the lower course of the river. The channel's capacity to hold water is thus reduced resulting in the overflow of the river banks causing damage to farms and other property. About $80 \%$ of women and a few $(20 \%)$ men are found cultivating crops such as rice and vegetables on these marginal lands. Reduced vegetation cover in the watersheds leads to less rainwater percolating into the soils, thus increasing surface run off which causes flash floods. The implication is that for the duration of the flash flood, the river channel is supplied with an unusually high volume of water, which it is not able to contain, thus causing floods.

\subsection{Effects of Flood on Household Livelihood}

Though flooding may have some positive contributions to terms of agricultural production but in disaster assessment, the negative impacts are of priority to development actors. Floods affect every aspect of the lives of the people. As predominantly agrarian communities, the flood disaster causes a lot of damage to crops and animals alike. Often, crops are submerged or washed off and animals drowned. In other cases, animals like sheep, goats and cattle go days without food and often suffer foot and mouth diseases and die as a result. Fowls are especially drowned as they get flooded. Table 3 shows the people's assessment of the effect of floods on their livelihoods. 
Table 3. Livelihoods activities.

\begin{tabular}{lll}
\hline Effects & Frequency & $\mathbf{\%}$ \\
\hline Loss of crops & 57 & 57 \\
Loss of animals & 26 & 26 \\
Loss of business & 5 & 5 \\
All of the above & 12 & 12 \\
Total & 100 & 100 \\
\hline
\end{tabular}

In table 3 , households consented that floods destroy their livelihoods, farms, animals and small scale businesses and increase their vulnerability through impoverishment. Figure 3 is a picture showing a farm flooded with water in one of the communities. Flood water inundates farms especially along the valley areas causing massive crop failures and poor yields. Crops like maize, groundnut, millet, beans etc. suffer poor yields due to too much water and this threatens food security of almost every household in the study communities.

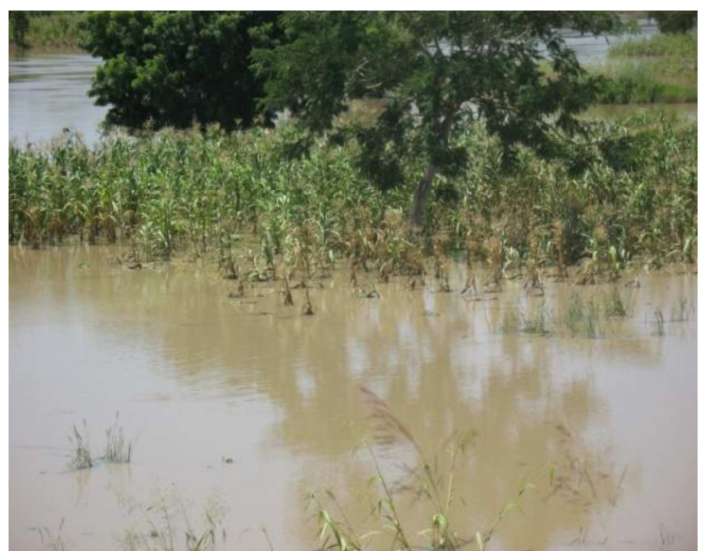

Figure 3. A picture of a farm flooded with water in one of the communities.

\subsection{Effect of Flood on Infrastructure}

A considerably high percentage of respondents reported damage to their shelter in the study communities. In Builsa, many of the houses are constructed with locally available materials and these are susceptible to damage by heavy rain, wind and flooding. Respondents seemed to understand the limitations of these housing materials but few could afford to build concrete houses with cemented walls. Results indicated about $90 \%$ of the housing stock are built with mud with the remaining $10 \%$ being built of cement blocks. The main roofing materials are thatch with wood and grass constituting $52 \%$, corrugated metal sheets $13 \%$, mud $35 \%$. Floors of houses were mostly constructed of mud/earth $56 \%$, cement/concrete $38 \%$, and stone $6 \%$. Majority of households live in compound houses $100 \%$ of which were self-owned. Housing quality index is an important indicator of flood vulnerability. Households in a grass-thatched house were perceived to be more vulnerable to floods than a household in a concrete house, whose housing structure represents high coping capacity and more resilience to flood hazards. To prevent flood waters entering their homes, it was observed that houses were constructed with reinforced material. All homesteads had houses built on raised land. The walls and entrances were elevated with small quantities of cement to protect their houses.

\subsection{Health, Water and Sanitation}

The sampled households indicated that they do not have health facilities in their communities. Mobile health teams from Sandema (the capital town of the Builsa District) and other health centres visit the communities on routine basis to offer health services to the people at outreach clinic points. It was revealed however that households experienced disruption in access to health services due to damaged roads and bridges as a result of floods. The research revealed that out of the 100 sampled households, $89 \%$ indicated having at least one member of their household getting sick during the floods. The most significant diseases experienced among the sampled households were malaria/fever $56 \%$, diarrhoea $21 \%$ and cough $15 \%$. Furthermore, $8 \%$ of the sampled households indicated that they experienced other disease such as scabies, sores and rashes during the floods which the respondents made use of traditional medicine. It was only when a member of the household become gravely ill that orthodox medical care was sought.

The study established that $63 \%$ of respondents use wells, followed by $37 \%$ who used rivers/streams as their major sources of water both for drinking and domestic use. During the flood period $70 \%$ of those who used rivers as their main source had their water affected as compared with $30 \%$ of those who relied on wells.

Waste disposal continues to be a problem in the district. The absence of toilets in the communities gives way to indiscriminate/open defecation, which is $94 \%$ of the sampled households had no sanitary facilities; they used the bush and rivers as alternatives. The bush and river in this circumstance of sanitation are usually regarded as no sanitary facility even though they are used as alternatives for excreta disposal. The rest of the $6 \%$ use public toilets at the primary schools in their communities. Also, as stated earlier that some of the community members use water from the river for domestic purpose also show how vulnerable these people can be to diseases if they are also found defecating into the same river.

\subsection{Relief Services}

The emergency relief policy guidelines of Ghana Government requires that local authorities such as National Disaster Management Organization (NADMO) is responsible for the management of areas affected by disasters and similar emergencies, for the rehabilitation of persons affected by disasters and again provide basic necessities such as food, shelter and medical care to disaster victims. The only time relief support services were near adequacy throughout the communities was during the 2007 floods which assumed a national crisis and attracted international support. Although over $80 \%$ of the respondents attest to having experienced flooding before, few acknowledged ever receiving official support. Out of the 100 households interviewed, $39 \%$ confirm ever receiving relief items. Furthermore, the findings revealed that during extreme flood events, affected families 
vacated their homes and moved to camps or were accommodated by relatives and friends. The study found that those who were accommodated in temporary flood shelters put up by the government and NGOs received the most assistance whereas the majority of those accommodated by neighbours and relatives received little or no assistance. This was because it was difficult to coordinate relief to the scattered households in the affected communities. Although some respondents confirmed receiving relief support, the majority of them felt the aids were not sufficient and were inappropriately handled and distributed. They were therefore forced to resort to household level adjustments to compensate for damages caused by the floods.

\subsection{Coping Strategies}

Rural communities across the developing world use various coping strategies in response to poverty, food insecurity, conflict as well as environmental stresses like flood and drought [6]. Floods have short to long term impact on livelihoods of the inhabitants. The short-term effects of floods included destruction of farmlands, soil erosion and pollution of drinking water and the impact on crop which contributes to low productivity and food security. In the long term impact, floods have their toll on food reserves in households which stretches hunger period from two months to six months and make household food security situation worse. The most common response in dealing with loss of crops in these areas was to wait for the next season to plant. Households borrowed seeds to plant from relatives, neighbours and friends. Some families sold livestock to buy seeds. The study also found that the households had to rely more on legumes than cereals for immediate food needs, they ate crops prematurely on the fields before harvest was due, they sold their labour for cash or food, hunted for wild animals and ate wild fruits like shea, baobab, dawadawa or reduced the quantity of food eaten or skipped some meals. They also borrow money and food in order to survive through the flood season. In extreme circumstances some households traded their assets for money and food, taking children out of schools to work, while some sent family members out to live with friends and relatives elsewhere; especially the young ones. These are some of the distress coping strategies that were mentioned by study participants.

To cope with loss in the case of pastoral farming, the responses included sending animals to areas where water and pasture is available or allow animals to roam in search of feed and water. Other coping actions include, treating livestock and selling the weak and vulnerable animals out.

Also the community members engaged in other activities such as sale of firewood or charcoal, income from petty trading usually by women, some travel to work mostly in the south and send food items home, thatch weaving for local roofing and twine weaving to make an income.

\subsection{Factors Influencing the Choice of Coping Strategies}

Socio-economic factors are important in choice of coping strategy, particularly those of age, education and wealth. During floods, older households are more likely to rely on social support to access basic levels of food and other resources than younger households.

Education was also found to be an influencing factor of coping. Most educated households relied more on savings, due to livelihood diversity. However less educated households undertook various livelihood strategies such as relying on social support and depending more on customary activities like agricultural techniques to cope with floods. Customary livelihoods were supplemented with livestock keeping, economic activities such as petty trading or servicebased activities like labour exchange. Feinberg [6] indicated that the frequent need for disaster survivors to relocate creates unique crisis problems. He stressed that relocation is associated with higher levels of stress, crowding, isolation, and social disruption. For example, it contributes to the social, environmental, and psychological stress experienced by disaster survivors.

\subsection{Institutional Arrangements and Responses to Flooding}

The National Disaster Management Organization (NADMO) is established to deal with disaster issues in Ghana. In the National Disaster Management Organization Act, 1996 (ACT 517), NADMO has the mandate to prepare disaster plans, monitor and evaluate the plans. Further, NADMO has to provide facilities for public awareness, warning systems and general preparedness for communities. Reducing the risks of flooding by the Government of Ghana is captured in both the Environmental Sanitation Policy (ESP, 2010) and National Water Policy (NSP, 2007). In the National Water Policy (2007), Government aims to construct flood protection structures at appropriate locations, apply appropriate technologies to provide the necessary information for detection and early warning systems for floods and drought, ensure that land-use planning/building regulations are adequate and enforced in respect of waterways and flood-prone areas; ensure rainwater harvesting techniques are incorporated into the building code and enforced and ensure implementation of mitigation strategies in consultation with affected communities. On the other hand the District Assemblies are to ensure that communities are provided with adequate and consistently functioning drainage works in accordance with nationally defined design standards, ensure appropriate bye laws and control mechanisms. The district assembly has been trying to control the activities within the low lying areas by mapping the land use plan and in corporation with other related local government institution to enforce laws regarding land activities. This policies and maps describe the kind of activities that are allowed within the flood prone areas, such as settlement, commercial areas among others. However the implementations of these policies are likely not as easy as planned [8]. Flooding within the district is still a major problem for the local government. Many communities have been long suffering with flood related issues for a long time now. 


\section{Conclusion and the Way Forward}

The analysis of the results led to the conclusion that, flood hazards are natural phenomena, but damages and losses from floods are the consequence of human action. Communities are particularly vulnerable to flooding due to changes to ecosystem which include, bad farming practices that replace natural and absorptive soil cover, deforestation of vegetation cover, soil erosion and the silting up of drainage channels which has the effect of increasing water movement to rivers faster than it did under natural conditions. Majority of the people including the government are not adequately prepared for the level of devastation that usually associated with such flood events. The short to medium and long term havoc on livelihoods of the populace included destruction of farmlands, soils erosion and pollution of drinking water. The medium term included, destroying agricultural produce thereby posing the risk of hunger to those engaged in subsistence farming. In the long-term, floods have serious effects on food reserves in households which stretches hunger period from two months to four months and makes household food security situation worse.

The evidence is that flood risk is increasing and continuing vigilance is needed to ensure that existing systems are maintained and improvements introduced. Recent years have seen a shift in emphasis associated with flooding from disaster response to preparedness and mitigation, and from the provision of services to more community-driven initiatives. At the institutional level, the establishment or improvement of monitoring and early warning systems that can ensure prompt and adequate preparation and response to disasters is seen as part of a preventive development strategy. Again preventive strategies can be made more effective if the capacity and the will are there, the priorities are right, legal and institutional frameworks are developed, policies implemented and the planned activities are well coordinated. While disasters cannot be prevented, measures need to be taken to reduce the extent of damage, especially in a developing country like Ghana whose population is increasing with scarce resources and facilities.

A number of actions that can be taken by both agencies and the public to mitigate the adverse impacts of flooding and this should include agencies improving their flood forecasting and warning systems, public awareness of flood risks should be highlighted through annual national awareness-raising campaigns.

There should be policies that target the marginalised in society, such as women, children, elderly, or the poor otherwise these groups will remain most vulnerable. For instance policy must support households to diversify income activities to continue to cope in times of flood or drought.

Self-help measures to reduce damage to property and stress caused by flooding should be encouraged, thereby reducing some of the negative consequences on the people. Creation of awareness among people living in disaster-prone areas of the risk they face and how best to respond when it occurs can be done to enhance local people's confidence and empower them to act when faced with danger and the construction of dams should be considered to trap the excess water which could be used for irrigation.

The people must be empowered to respond effectively to contributing to the development of their own communities on a sustained basis. Community involvement and their active participation should be encouraged in order to gain greater insight into the individual and collective perception of development and risk, and to have a clear understanding of the cultural and organizational characteristics of each society as well as its behaviour and interactions with the physical and natural environment, this will cultivate increased participation among the local community to deal with the effects of the disaster. Successful flood risk management should therefore be dependent upon the active support of all on whom the effects of flooding may impact, those directly at risk, the civil authorities and the wider community.

\section{References}

[1] Action Aid (2005). Participatory Vulnerability Analysis: A Step by Step Guide for Field Staff. London: Action Aid International.

[2] Action Aid (2006). Climate Change, Urban Flooding and the Rights of the Urban Adaptation to Environmental Risk. London: Action Aid International

[3] Africanews (2017). Ghana Hit by Deadly Floods in the Northern Region

http://www.africanews.com/2017/07/27/ghana-hit-by-deadlyfloods-in-the-northern-region-vp-visits-victims// (Retrieved on $27^{\text {th }}$ July, 2017).

[4] Blaikie, P. Cannon, T. Davis I and Wisner, B. (1994). At risk: Natural Hazards, Peoples Vulnerability and Disaster. London: Routledge.

[5] Blaikie, P. Cannon, T. Davis I and Wisner, B. (2003). At risk: Natural Hazards, Peoples Vulnerability and Disaster. London: Routledge.

[6] Builsa District Assembly, (2010). 2010-2013 Medium Term Development Plan Sandema Upper East Region. Builsa District Assembly

[7] Feinberg, T. (1999). The midwest floods of 1993: Observations of a natural disaster. In A. S. Canter \& S. A. Carroll (Eds.), Crisis prevention \& response: A collection of NASP resources (pp. 223-239). Bethesda, MD: National Association of School Psychologists.

[8] Food and Agriculture Organisation, (2008). Financing Climate Change Adaptation and Mitigation in the Agriculture and Forestry Sectors, FAO and IFAD, Rome.

[9] Ghana Statistical Service, (2005). Population and Housing Census 2000, Special Report on Localities by District Upper East Region GSS, Accra.

[10] Intergovernmental Panel on Climate Change (IPCC), (2001). Climate change 2001: synthesis report; a report of the Intergovernmental Panel on Climate Change UK. 
[11] International Panel on Climate Change (IPCC) (2012): Climate Change 2001 Synthesis Report Summary for Policy Makers.

[12] International Federation of Red Cross (IFRC) (2017): Emergency Plan of Action (EPoA) Ghana Floods.

[13] National Disaster Management Organisation (2007), National Disaster Management Assessment Report, Builsa District, Upper East Region.

[14] Strydom, H., Fouche C. B. and Delport C. S. L (Third edition). 2005. Research at Grassroots for Social Sciences and Human Service Professions Switzerland p193.

[15] UNDP/NADMO, (2009). Enhancing National Strategies for Effective Disaster Risk Reduction in Ghana.

[16] United Nations International Strategy for Disaster Reduction (UNISDR), (2004). Living with risk: a global review of disaster reduction initiatives, United Nations.

[17] Reliefweb (2017). Ghana: Floods Emergency Plan of Action (EPoA) DREF Operation no. MDRGH014, Reliefweb. 